\section{International Scientific Journal Theoretical \& Applied Science}

Nikolay Vasilevich Penshin candidat of economic sciences, Head of the Department "Organization of transportation and road safety" Tambov state technical University, Russia avtobd@mail.ru

Victor Yurievich Ivlev

Undergraduate, Mechanical engineer Aor Nekrasovskoe RTP, city of Rasskazovo, Russia victor.pshenihniy_7@mail.ru

SECTION 27. Transport.

\title{
TRAFFIC ACCIDENT WITH PARTICIPATION OF LEGAL ENTITIES AND INDIVIDUALS IN THE TAMBOV REGION
}

\author{
Abstract: The article reveals the problems for the Commission of road accident with participation of legal and \\ physical persons. \\ Key words: Legal entities, physical persons, accidents, Tambov region. \\ Language: Russian \\ Citation: Penshin NV, Ivlev VY (2015) TRAFFIC ACCIDENT WITH PARTICIPATION OF LEGAL \\ ENTITIES AND INDIVIDUALS IN THE TAMBOV REGION. ISJ Theoretical \& Applied Science 12 (32): $113-$ \\ 117. \\ Soi: http://s-o-i.org/1.1/TAS-12-32-22 Doi: crossef http://dx.doi.org/10.15863/TAS.2015.12.32.22 \\ УДК 502.7

\section{ДОРОЖНО-ТРАНСПОРТНЫЕ ПРОИСШЕСТВИЯ С УЧАСТИЕМ ЮРИДИЧЕСКИХ И ФИЗИЧЕСКИХ ЛИЦ ПО ТАМБОВСКОЙ ОБЛАСТИ}

\author{
Аннотация: В статье выявляется проблематика по совершению ДТП с участием юридических и \\ физических лич. \\ Ключевые слова: Юридические лица, физические лица, ДТП, Тамбовская область.
}

Актуальность данной темы обусловлена обстановкой в сфере обеспечения безопасности дорожного движения. Ежегодно в России в дорожно-транспортных происшествиях погибают около 30 тысяч и получают ранения свыше 180 тысяч человек. Высокие темпы автомобилизации создают дополнительные предпосылки ухудшения в сфере обеспечения безопасности дорожного движения. В настоящее время на 1000 россиян приходится более 100 автомобилей и, как показывает опыт развитых стран, Россия вступила в так называемую стадию «взрывного роста», которая будет продолжаться до достижения уровня насыщения порядка 300-400 автомобилей на 1000 человек. Эта стадия является и характеризуется резким осложнением обстановки с обеспечением безопасности движения, ростом дорожно-транспортного травматизма. К этому следует добавить, что улично-дорожная часть страны не соответствует фактической интенсивности транспортных потоков. Основные магистрали перегружены в 23 раза. Не отвечает установленным требованиям и техническое состояние большинства автомобильных дорог. Остается неудовлетворенным состояние транспортной дисциплины участников дорожно-транспортного движения. Широкое распространение получили нарушения, связанные с сознательным невыполнением установленных требований. [3, с. 12].

Отметим, что из-за несовершенства транспортных систем безопасности на дорогах в настоящее время гибнет людей больше чем в локальных военных конфликтах, и поэтому тема в данное время актуальна.

В дорожно-транспортных происшествиях оказываются как юридические, так и физические лица. Рассмотрим это более подробно на Тамбовской области.

За 2014 года дорожно-транспортная обстановка на территории Тамбовской области несколько изменилась по сравнению с 2013 г. Количество дорожно-транспортных происшествий увеличилось на 3 факта (2012-319, 2013-322, 2014 - 340) (+0.9\%), количество 
погибших осталось на прежнем уровне (2012-51, 2013-51, 2014 54) (+0.0\%), число раненых увеличилось на 34 человека (2012-460, 2013-494, 2014 - 504) (+7.4\%). Покажем графически. [6, с.4].

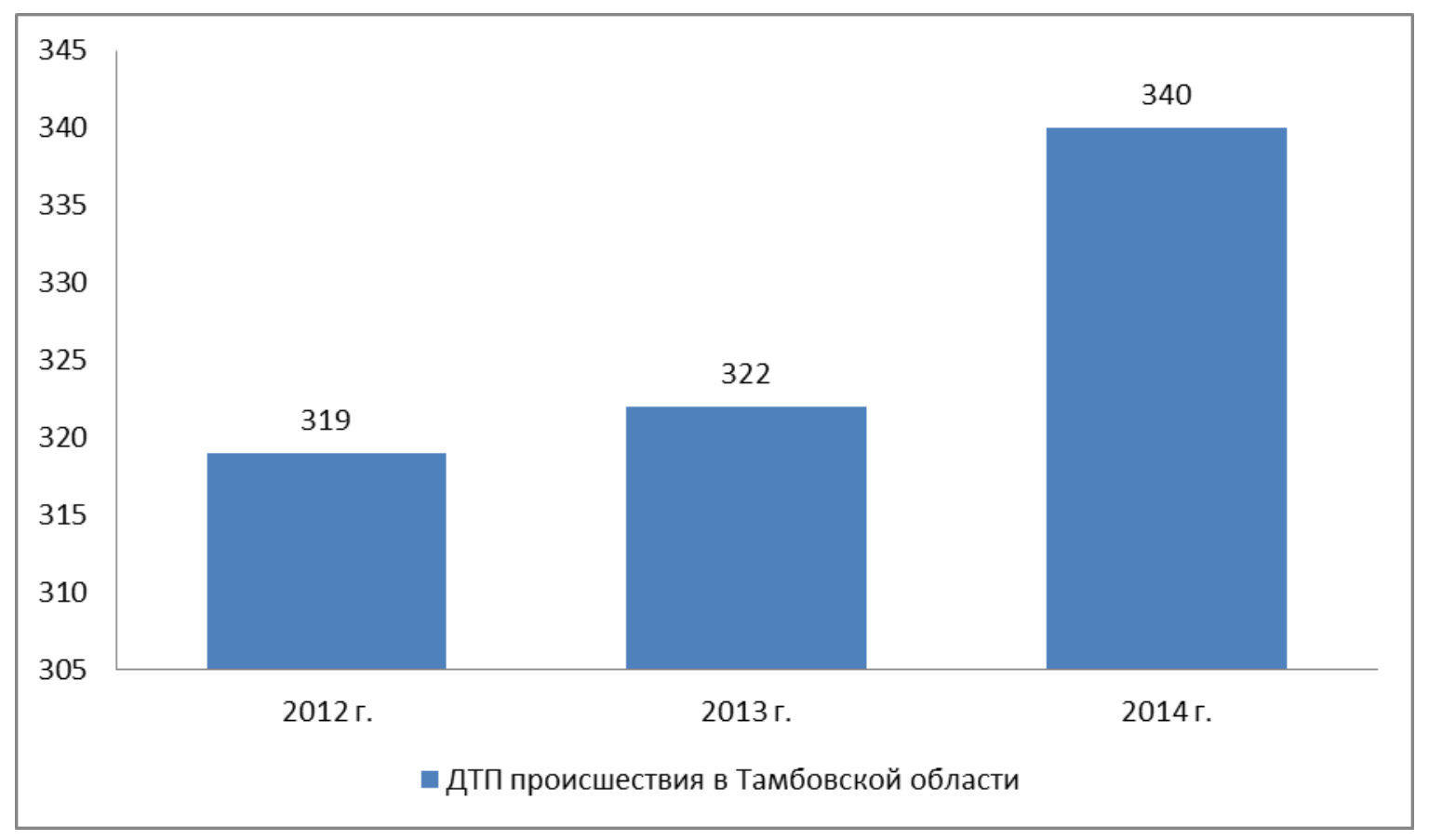

Рисунок 1 - Дорожно-транспортные происшествия в Тамбовской области.

Очень большое количество происшествий происходит с участием не только физических лиц, но и юридических лиц на автодорогах.

Автодороги федерального значения (М6Каспий, Орел-Ливны-Тамбов, Тамбов-Пенза, Воронеж-Тамбов, Северный и Южный обход г. Тамбова, Подъезд к г. Тамбов) Общее количество дорожно-транспортных происшествий на автодорогах федерального значения увеличилось на 2 случая (2012-149, 2013-151) (+1.3\%). При этом число погибших снизилось на 11 человек (2012-37, 2013-26) (-29.7\%), число раненых увеличилось на 54 человека (2012-222, 2013-276) (+24.3\%). ДТП, произошедших по вине нетрезвых водителей увеличилось на 6 случаев (2012-2, 2013-8) (+300.0\%). [3, с. 5].

Автодороги регионального значения (Тамбов-Шацк, Тамбов-Котовск) Общее количество дорожно-транспортных происшествий на автодорогах территориального значения увеличилось на 11 случаев (2012-52, 2013-63) (+8.5\%). При этом число погибших увеличилось на 6 человек (2012-6, 2013-12) $(+100.0 \%)$, число раненых увеличилось на 7 человек (2012- 91, 2013-84) (+7.7\%). ДТП, произошедших по вине нетрезвых водителей увеличилось на 1 случай $(2012-3,2013-4)$ $(+33,3 \%)$. Покажем графически. [6, с. 6].

Сведения об аварийности с участием ТС юридических лиц. За 2014 года на территории обслуживания было зарегистрировано 47 ДТП $(2014-46) \quad(+2.2 \%)$ с участием транспортных средств юридических лиц. При этом количество погибших осталось на прежнем уровне (2012-9, 2013-9, 2014 - 10) (+0.0\%), а количество раненых увеличилось на 7 человек (2012-75, 2013-82, 2014 85) $(+9.3 \%)$. [5, с. 5].

По вине водителей транспортных средств юридических лиц зарегистрировано 25 ДТП (2013-20) (+25.0\%), при этом количество погибших снизилось на 2 человека (2013-5, 20143) (-40.0\%), а количество раненых увеличилось на 12 человек (2013-29, 2014-46) (+58.6\%). Сведения об аварийности с участием автобусов. За 2014 года на территории обслуживания было зарегистрировано 8 ДТП (2014-16) (-50.0\%) с участием автобусов.

При этом количество погибших уменьшилось на 7 человек (2012-7, 2013-0, 20141) $(-100.0 \%)$, а количество раненых снизилось на 3 человека (2012-35, 2013-32, 2014 - 33) (-8.6 \%). По вине водителей транспортных средств осуществляющих пассажирские перевозки зарегистрировано 5 ДТП (2012-9) (-44.4\%), при этом количество погибших снизилось на 5 человек (2012-5, 2013-0) (- 100.0\%), а количество раненых снизилось на 4 человека (2013-24, 201420) (- 16.7\%). Удельный вес от общего количества ДТП составил 20.5. При этом число погибших увеличилось на 6 случаев (2012-6, 2013-12, 2014 - 


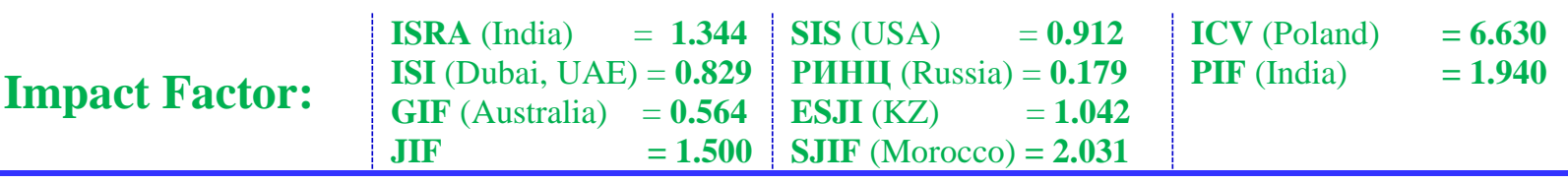

13) (+100.0\%), а число раненых увеличилось на 44 человека (2012-70, 2013-114, 2014 - 115)

Проведем сравнительную характеристику по $(+62.2 \%)$. [6, c. 3].

дорожно-транспортным

физических и юридических лиц.

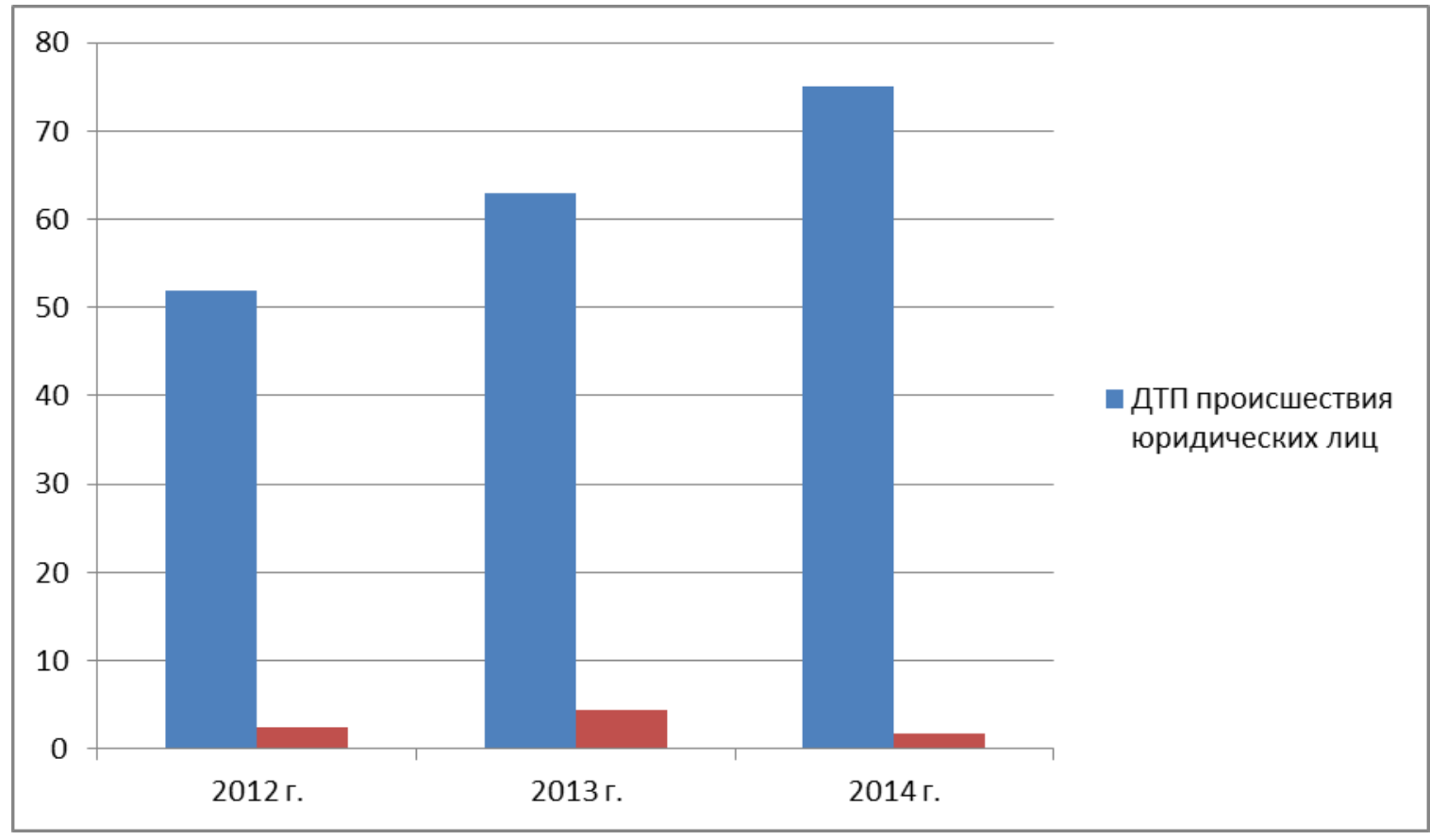

Рисунок 2 - ДТП происшествия на автодорогах юридических лиц.

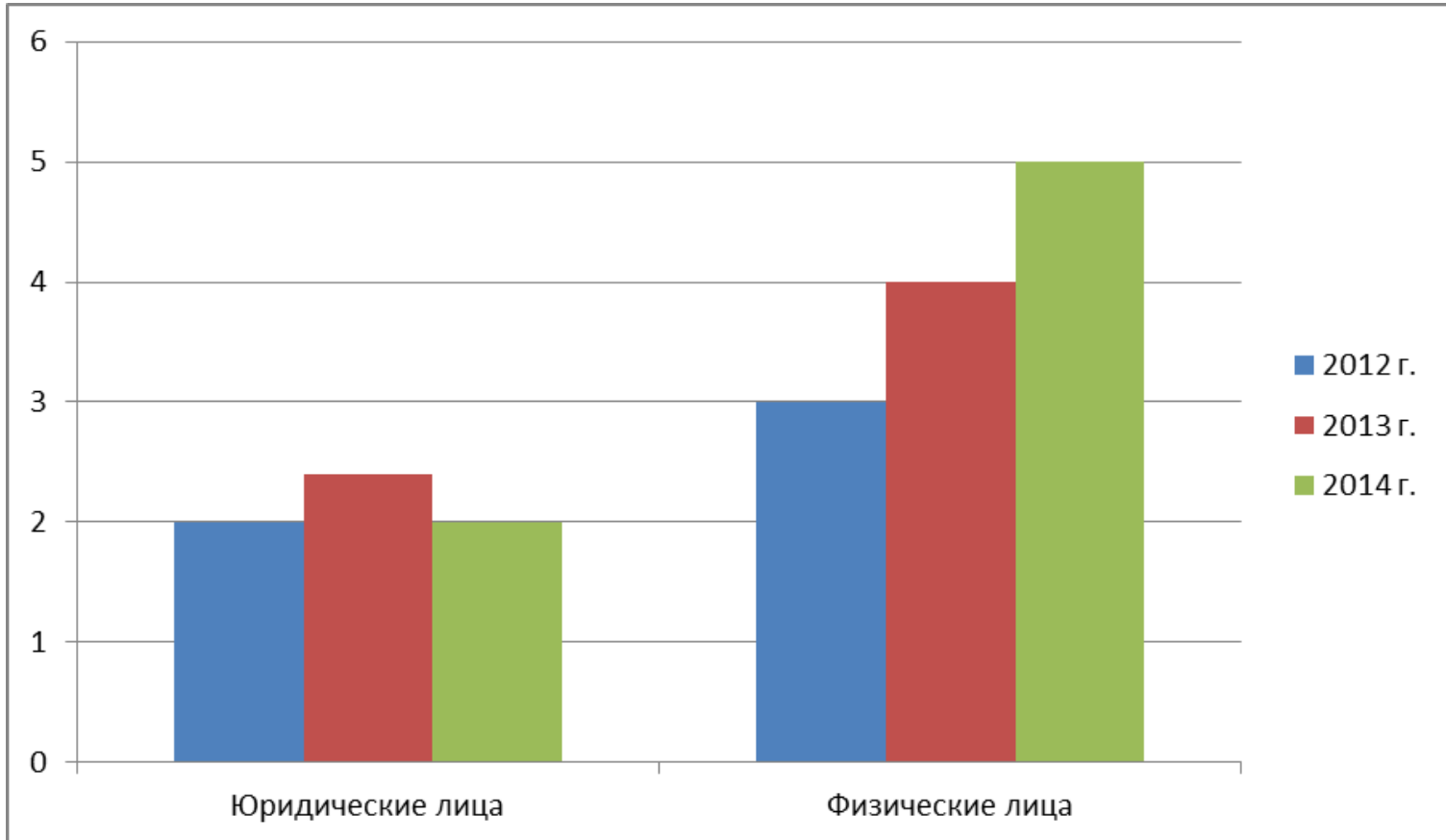

Рисунок 3 - Сравнительная характеристика дорожно-транспортных происшествий юридических и физических лиц в Тамбовской области.

Из графика видно, что ДТП больше совершается физическими лицами, чем юридическими. Это связано, с тем, что с юридически лицами проводятся дополнительные 
обучения, профилактические работы. С физическими лицами кроме штрафа, или лишения прав, ничего дополнительного не проводится.

С целью профилактики аварийности и снижения тяжести последствий по Тамбовской области с юридическими лицами проводилась и проводится определенная работа. Например, в 2013 г. проведено 45 рейдовых мероприятий по выявлению и пресечению грубых нарушений ПДД, а также нарушений ПДД, являющихся основными причинами ДТП. Возбуждено 612 дел об административных правонарушениях.

Сотрудниками отделения ГИБдД ОМВД России по Тамбовскому району за отчетный период было наложено 1212 административных штрафа на сумму 2354250 рублей (2012-618 на сумму 1008150 рублей), из них взыскано 1154 штрафов на сумму 1583450 рублей (2012-589 на сумму 580550 рублей). Осталось не взыскано 58 административных штрафов. При этом процент взыскания по количеству составил 95.2\% (201295.3\%), при среднем областном показателе 79.9\%, процент взыскания по сумме составил $67.3 \%$ (2012-57.6\%) при среднем областном показателе $80.5 \%$. [6, c. 2].

Кроме того, были организованы и проведены целевые рейдовые мероприятия, направленные на выявление и привлечение к административной ответственности по ч. 1 ст. 20.25 КоАП РФ лиц, не уплативших административные штрафы в установленный законом срок.

В результате проделанной работы сотрудниками отделения ГИБДД составлено 42 протокола по ч.1 ст. 20.25 КоАП РФ (-20.8\% к 2012). - за отчетный период на рассмотрение в мировые и районные суды направлено 127 дел об административных правонарушениях, из которых по 13 делам принято решение в виде лишения права управления транспортными средствами, по 78 делам - в виде административного штрафа, по 20 делам - в виде административного ареста, 1 дело об административном правонарушении было прекращено судом из-за недоказанности. 15 дел в настоящее время находится на рассмотрении в судах.

В целях усиления контроля за юридическими лицами с пассажирским транспортом на постоянной основе проводится профилактическая работа.

Так, за 2014 г. проведено 12 плановых и 20 внеплановых проверок АТП, в ходе которых должностным лицам АТП выдано 23 предписаний на устранение выявленных недостатков. Выявлено 95 транспортных средств юридических лиц с техническими неисправностями, при которых запрещена их эксплуатация, водители данных транспортных средств привлечены к административной ответственности. За нарушение требований законодательства РФ о проведение предрейсового медицинского осмотра водителей, а также проведения предрейсового технического осмотра ТС к административной ответственности по ст. 12.31.1 привлечено 17 должностных и 7 юридических лица. В автохозяйствах проведено 197 бесед профилактической направленности. За 2014 г. проверено 10 пассажироперевозщиков.

В дальнейшем, в целях снижения роста аварийности планируется проведение следующих мероприятий:

1. Учитывая данные анализа аварийности на территории Тамбовского района, а также причины и условия возникновения дорожнотранспортных происшествий проводить в 2015 году еженедельные рейдовые мероприятия, направленные на выявление и пресечение нарушений ПДД РФ с привлечением сотрудников других служб ОМВД России по Тамбовскому району, а также сотрудниками СБ ОР ДПС ГИБДД УМВД России по Тамбовской области.

Необходимо провести работу, направленную на снижение аварийности с участием транспортных средств юридических лиц, осуществляющих пассажирские перевозки. А именно: - увеличить количество проводимых профилактических бесед с руководящим и водительским составом о недопустимости нарушения ПДД РФ; - в случае совершении дорожно-транспортных происшествий, при котором пострадали люди с участием транспортных средств, принадлежащих юридическим лицам, назначать государственных инспекторов технического надзора соисполнителями сотрудников ГИБДД осуществлящих по факту ДТП административное расследование и проводить проверку по данным фактам с целью установления причин и условий возникновения ДТП, а также выявления нарушений законодательства РФ. По фактам выявленных при этом нарушений проводить проверку в отношении должностного и юридического лица, выносить руководителям организаций предписания об устранении выявленных недостатков. По фактам невыполнения требований предписания составлять соответствующий административный материал с последующим информированием органов прокуратуры - провести целевые рейдовые мероприятий, в ходе которых организовать проверку автобусов осуществляющих перевозку пассажиров на коммерческой основе на конечных остановках на предмет несоответствия конструкции требованиям законодательства РФ. В случае выявления нарушений принимать меры 


\begin{tabular}{|c|c|c|c|c|c|c|}
\hline Impact Factor: & $\begin{array}{l}\text { ISRA (India) } \\
\text { ISI (Dubai, UAI } \\
\text { GIF (Australia) } \\
\text { JIF }\end{array}$ & $\begin{array}{l}=1.344 \\
=0.829 \\
=0.564 \\
=1.500\end{array}$ & $\begin{array}{l}\text { SIS (USA) } \\
\text { PИНЦ (Russia } \\
\text { ESJI (KZ) } \\
\text { SJIF (Moroccc }\end{array}$ & $\begin{array}{l}=0.912 \\
=0.179 \\
=1.042 \\
=\mathbf{2 . 0 3 1}\end{array}$ & $\begin{array}{l}\text { ICV (Poland) } \\
\text { PIF (India) }\end{array}$ & $\begin{array}{l}=6.630 \\
=1.940\end{array}$ \\
\hline
\end{tabular}

воздействия,

предусмотренные

законодательством РФ.

На постоянной основе проводить работу по профилактике аварийности с участием детей и несовершеннолетних, с привлечением сотрудников РОУ Тамбовского района, а также сотрудников ПДН ОМВД России по Тамбовскому району. Ежемесячно анализировать состояние детского дорожно-транспортного травматизма и использовать результаты в профилактической деятельности подразделения ГИБДД и образовательных учреждений. Проводить целенаправленную работу с родителями по соблюдению Правил дорожного движения. Привлекать взрослых к профилактической работе в образовательных учреждениях, проводить совместные мероприятия с участием родителей и детей. По всем фактам совершения дорожно-транспортных происшествий с участием несовершеннолетних проводить служебные проверки, а в случаях совершения дорожно-транспортных происшествий по вине несовершеннолетних проводить обследование образовательных учреждений, в которых учатся дети совместно с представителями Управления образования Тамбовской области. [6, с. 7].

С целью снижения количества мест концентрации ДТП на основе анализа аварийности, провести совместно с представителями дорожных организаций обслуживающих конкретную автодорогу, обследование эксплуатационного состояния улично-дорожной сети Тамбовской области. При совершении дорожно-транспортного происшествия, с неудовлетворительными дорожными условиями, проводить осмотр места ДТП в присутствии соответствующих должностных лиц дорожных организаций с целью определения характеристик дорожных условий на момент совершения ДТП и составления соответствующего акта. По всем фактам выявления нарушений принимать меры воздействия, предусмотренные законодательством РФ.

С целью повышения взыскаемости наложенных административных штрафов проводить беседы с лицами, обращающимися в Госавтоинспекцию на предмет оплаты в установленный законом срок штрафа, с обязательной проверкой по АИПС «Административная практика» ГИБдД. В случае установления фактов неоплаты штрафа принимать к лицам меры административного воздействия. Будем надеяться, что в дальнейшем планируемая профилактическая работа с юридическими и физическими лицами даст положительные результаты и приведет к снижению аварийности и тяжести последствий при ДТП, а также повышению безопасности дорожного движения в Тамбовской области.

\section{References:}

1. Babkov VF (2012) road [Text] : textbook for high schools / V. F. Babkov. - Moscow: Transport, 2012. $-280 \mathrm{p}$.

2. Evdokimov EA (2014) Road traffic injuries and emergency medicine // Emergency Medicine, 2014 No. 12. pp. 12-19.

3. Kulikov NA, Vdovin ES (2014) Comparative characteristics of regions - subjects of the Russian Federation in the Central Federal district on the quality of life of the population on the basis of capitalized assets (on the example of Tambov region) // Tambov State University, 2014, No. 9 (89).

4. Nemchinov MV (2014) Again about the quality of // a road No. 2, 2014. pp. 74-77.

5. (2006) The " Procedural, N. In. Road transport in the conditions of market economy / N. In. The " procedural // Tambov state technical
University. - 2006. - Vol. 12, No. 2 A. - pp. $448-457$.

6. (2014) Information about the status of accidents on the territory of Tambov rightaboutnow oblast for 2012-2014 with the participation of legal entities and individuals. r00.tmbreg.EN"fifiles/Spravka.pravka//esyaces/

7. Klinkovshteyn GI (2011) Or gan1izatsiya traffic: study Pozo Bie. - Moscow: Transport, 2011. - 246.

8. Konoplyanko VI (2011) Organlizatsiya dvizhelniya and road safety: the textbook. Moscow: Transport, 2011. - 1183.

9. (2012) The Zapolsky I. Y. Architecture-vehicleroad. Moscow: Transport. 2012. - 190.

10. (2015) Available: http://www.gibdd.ru/ (Accessed: 20.12.2015). 